\title{
Does lymph node ratio (metastasis/total lymph node count) affect survival and prognosis in gastric cancer?
}

\author{
Ramazan Topcu, MD, İbrahim T. Şahiner, MD, Murat Kendirci, MD, Murathan Erkent, MD, İsmail Sezikli, MD, \\ Mehmet B. Tutan, $M D$.
}

\begin{abstract}

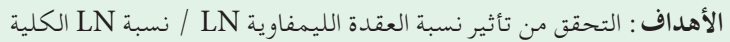
(N-Ratio) المعالج جراحياً.

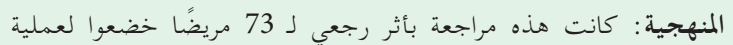

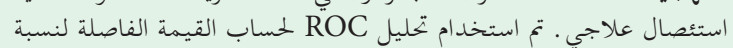
N للمرضى. تم تحديد قيمة القطع

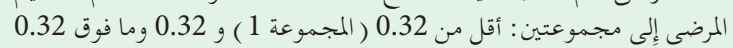

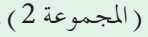

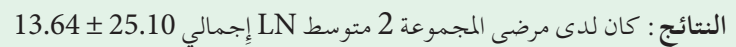

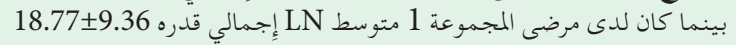

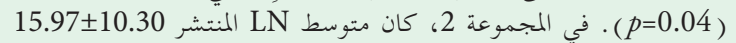

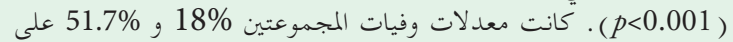

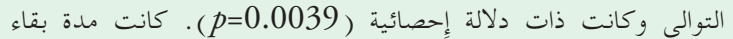

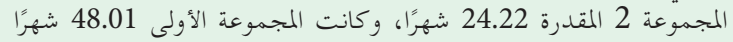

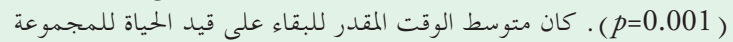

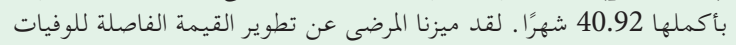

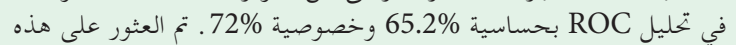

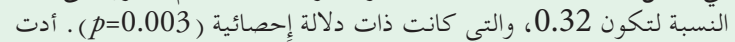

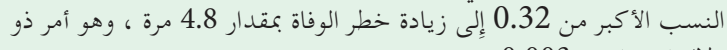
دلالة إحصائية (

المخلاصة : يمكن أن تكون نسبة N مقياسًا جد يدًا لتقييم الإنذار بعد استئصال

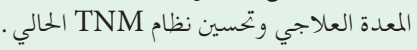

Objectives: To investigate the influence of the metastatic lymph node/total lymph node ratio ( $\mathrm{N}$-ratio) on survival and prognosis in surgically treated gastric carcinomas.

Methods: A retrospective review of 73 patients who underwent curative resection at the Department of General Surgery, Hitit University Faculty of Medicine, Turkey. Receiver operating characteristic analysis was used to calculate the cut-off value for the $\mathrm{N}$-ratio of the patients. The $\mathrm{N}$-ratio cut-off value was determined to be 0.32 . Patients were divided into 2 groups: below 0.32 (Group 1) and 0.32 and above 0.32 (Group 2).
Results: Group 2 patients had a total lymph node mean of $25.10 \pm 13.64$ while Group 1 patients had a total lymph node mean of $18.77 \pm 9.36(p=0.04)$. In Group 2, the mean of metastatic lymph node was $15.97 \pm 10.30 \quad(p<0.001)$. The mortality rate of Group 1 was $18 \%$ while Group 2 was $51.7 \%$, and were statistically significant $(p=0.0039)$. The estimated survival duration of Group 2 was 24.22 months, and Group 1 was 48.01 months ( $p=0.001)$. The mean estimated survival time for the entire group was 40.92 months. We differentiated patients from the development of mortality cut-off value in ROC analysis with $65.2 \%$ sensitivity and $72 \%$ specificity. This ratio was found to be 0.32 , which was statistically significant $(p=0.003)$. Ratios greater than 0.32 raised the risk of mortality by 4.8 times, which was statistically significant $(p=0.003)$.

Conclusion: The N-ratio could be a new metric to evaluate prognosis following curative gastrectomy and improve the existing tumor lymph node metastasis staging system.

Keywords: gastric cancer, N-ratio, survival, prognosis

Saudi Med J 2022; Vol. 43 (2): 139-145 doi: 10.15537/smj.2022.43.2.20210464

From the Department of General Surgery (Topcu, Şahiner, Kendirci, Sezikli, Tutan), Faculty of Medicine, Hitit University, Çorum; and from the Department of General Surgery (Erkent), Faculty of Medicine, Başkent University, Ankara, Turkey.

Received 4th September 2021. Accepted 7th December 2021.

Address correspondence and reprint request to: Dr. Ramazan Topcu, Department of General Surgery, Faculty of Medicine, Hitit University, Çorum, Turkey. E-mail: topcur58@gmail.com

ORCID ID: https//orcid.org/0000-0001-6214-4868

Disclosure. Authors have no conflict of interests, and the work was not supported or funded by any drug company. 
G astric cancer is the fourth most common cancer I worldwide and the third leading cause of cancerrelated death. ${ }^{1}$ The most common treatment for stomach cancer is surgery with chemotherapy (CT) or radiation (RT), and lymph node metastases is regarded the most important factor of postoperative survival. ${ }^{2}$ As a result, lymph node dissection is considered an important prognostic factor in gastric cancer.

For lymph node staging, at least 15 lymph nodes must be excised according to the American Joint Committee on Cancer (AJCC) staging standard for malignant tumors ( $\mathrm{pN}$ stage). ${ }^{3}$ In clinical practice, certain variables have resulted in an insufficient number of lymph nodes being dissected. The number of metastases diagnosed using normal $\mathrm{pN}$ staging was found to be affected by increasing the number of lymph nodes dissected. This could lead to a modification in the TNM (tumor lymph node metastasis) classification of cancer, which could impact prognostic accuracy. ${ }^{4-6}$

The AJCC-accepted TNM classification is the best prognostic classification approach for assessing the survival of gastric cancer patients in Western countries. In 1997, the number of metastatic lymph nodes (MLN) rather than their location became the basis for lymph node classification. ${ }^{7}$ In addition to being more useful and practical, classification based on the number of metastatic lymph nodes is superior and sensitive in terms of prognostic value versus classification based on the location of metastatic lymph nodes in many studies. ${ }^{8,9}$ To determine the right stage of the disease, the TNM classification requires the removal of at least 15 lymph nodes. ${ }^{3}$ According to studies, the average number of lymph nodes examined after radical resection in instances of stomach cancer in Western countries is 10 , and only $30 \%$ of patients have at least 15 lymph nodes removed. This is a component that can have a negative impact on proper staging. ${ }^{10}$ Furthermore, for both categories, a phase shift event is observed with a frequency of more than $15 \% .{ }^{11}$ With these problems, some investigators have proposed to use the metastatic lymph node ratio (N-ratio: number of metastatic lymph nodes/total number of lymph nodes evaluated [TLN]) instead of the total number of positive nodes in lymph node evaluation. The $\mathrm{N}$-ratio is an independent prognostic factor in radically resected gastric cancer cases according to studies conducted over the previous 20 years. ${ }^{12,13}$ This study aims to examine the influence of $\mathrm{N}$-ratio on survival and prognosis in curative resection of gastric cancers.

Methods. A total of 103 patients were treated for stomach cancer between January 2014 and December
2017 at the Department of General Surgery, Hitit University Faculty of Medicine, Turkey and were retrospectively searched from the hospital database and clinical archive system after receiving approval from the Hitit University Clinical Research Ethics Committee (20.01.2021-No: 375).

Of the 103 patients studied, 30 patients were excluded from the research because they were unresectable, had gastrointestinal stromal tumors as a result of pathology, and had undergone palliative surgery. A retrospective review of the clinical records, pathology reports, and surgical reports of 73 patients who underwent curative resection was then carried out.

Patients' demographics, tumor localization, surgical types and findings, post-operative histopathological types, presence, and types of postoperative complications, length of hospital stay, preoperative or postoperative CT or RT, total lymph node counts and metastatic lymph node counts, follow-up times, and mortality were all assessed. Cases that did not have any of these data were excluded. The cut-off value for the $\mathrm{N}$-ratio computation of the patients was calculated using a receiver operating characteristic (ROC) analysis. The $\mathrm{N}$-ratio cut-off value was determined to be 0.32 . Patients were divided into 2 groups: below 0.32 (Group 1) and 0.32 and above 0.32 (Group 2). The statistical difference between the 2 groups was examined using estimated mean survival analysis.

Categorical variables such as gender, number of additional diseases, tumor location, extent of surgery, presence of additional organ resections (such as: cholecystectomy or splenectomy), pathology results, presence and types of complications, presence of chemotherapy, and presence of mortality was reported as numbers and percentages. Numerical variables such as age, length of hospital stay, TLN, MLN, N-ratio ratio, follow-up time, and mean survival time were reported as mean value, standard deviation $( \pm)$, and median value. Pearson and Spearman correlation coefficients were used to examine the relationships between variables. By drawing the ROC curve and computing the area under it and the Youden index, the cut-off value for the MLN/TLN ratio that best distinguishes the groups according to mortality and has optimal sensitivity and specificity was determined.

Statistical analysis. The Chi-square test was used to assess the statistical difference in categorical variables between groups. The Shapiro-Wilks test was used to assess the normal distribution of numerical data. The mean ages of the 2 groups were compared using student's t-test. The Mann-Whitney U test was used to compare hospitalization time, TLC, MLN, N-ratio ratio, and 
follow-up duration between the 2 groups. The KaplanMeier survival analysis was used for survival analysis, and the log-rank test was used to determine statistical significance between the 2 groups. A $p$-value of $<0.05$ was considered significant. The Statistical Package for Social Sciences for Windows, version 26. (IBM Corp., Armonk, N.Y., USA) was used to conduct all statistical analyses.

Results. In the 73 patients included in the research, standard curative resection and D2 lymph node dissection were performed by a surgical team with similar surgical experience. Most patients were men $(n=56,76.7 \%)$. The mean age was $66.49 \pm 11.75$ years. No additional disease was found in most patients (54.8\%). Table 1 shows the demographic characteristics of the patients. Most lesions (41.09\%) were located in the antrum, and the most common surgical procedures were subtotal gastrectomy and D2 lymph node dissection (57.5\%). In 73 cases, simultaneous cholecystectomy was performed; gastrectomy was carried out in $8(10.95 \%)$ patients and splenectomy in $4(5.47 \%)$ patients tumors were least differentiated adenocarcinoma $(50.68 \%)$ and least differentiated adenosquamous carcinoma (1.36\%). Wound infection $(5.47 \%)$ and pulmonary embolism $(1,36 \%)$ were the most common complications. The patients' mean hospital stay was determined to be $10.11 \pm 4.77$ days. There were $62(84.9 \%)$ patients who received adjuvant chemotherapy. The mean number of total lymph nodes removed during surgery was $21.29 \pm 11.59$, while the average MLN removed was 7.63 \pm 9.56 . The N-ratio average was $0.32 \pm 0.31$. The patients were followed for a mean of $19.38 \pm 15.84$ months, and the overall mortality rate was $31.5 \%(n=23)$ over that time (Table 1$)$.

Patients were separated into 2 groups according to the N-ratio ratio: Group 1 with a cut-off value of $<0.32$ and Group 2 with a cut-off value of 0.32 and $>0.32$. (Table 2). In terms of gender distribution $(p=0.889)$, mean age $(p=0.947)$, and comorbidity $(p=0.669)$, there was no statistically significant difference between the 2 groups. Subtotal gastrectomy was performed in 16 patients and total gastrectomy in 12 patients in Group 1; subtotal gastrectomy was performed in 26 patients and total gastrectomy in 18, out of 44 patients in Group 2. No statistically significant difference was determined between the groups in terms of the method of surgery $(p=0.74)$. In terms of additional organ resection, there were no statistically significant differences between Group 2 ( $p=0.892)$ and Group 2 ( $p=0.536$ ).

No statistically significant difference was found between both groups in terms of length of hospital stay
Table 1 - Demographic characteristics of the patients $(\mathrm{N}=73)$.

\begin{tabular}{|c|c|}
\hline Characteristics & n (\%) \\
\hline \multicolumn{2}{|l|}{ Gender } \\
\hline Male & $56(76.7)$ \\
\hline Female & $17(23.3)$ \\
\hline \multicolumn{2}{|l|}{ Age } \\
\hline Mean \pm SD & $66,49 \pm 11,75$ \\
\hline Min-max (median) & $43-91(67)$ \\
\hline \multicolumn{2}{|l|}{ Presence of comorbidities } \\
\hline No & $40(54.8)$ \\
\hline Yes & $33(45.2)$ \\
\hline \multicolumn{2}{|l|}{ Tumor localization } \\
\hline Cardia & $3(4.1)$ \\
\hline Corpus & $16(21.91)$ \\
\hline Big curvature & $9(12.32)$ \\
\hline Small curvature & $14(19.17)$ \\
\hline Antrum & $30(41.09)$ \\
\hline Pylorus & $1(1.36)$ \\
\hline \multicolumn{2}{|l|}{ Surgery technique } \\
\hline Subtotal gastectomy+D2 lymph node dissection & $42(57.5)$ \\
\hline Total gastrectomy + D2 lymph node dissection & $31(42.5)$ \\
\hline \multicolumn{2}{|l|}{ Additional organ resection } \\
\hline Cholecystectomy & $8(10.95)$ \\
\hline Splenectomy & $4(5.47)$ \\
\hline \multicolumn{2}{|l|}{ Pathology } \\
\hline Well differentiated adenocarcinoma & $2(2.73)$ \\
\hline Moderately differentiated adenocarcinoma & $22(30.13)$ \\
\hline Poorly differentiated adenocarcinoma & $37(50.68)$ \\
\hline Signet ring cell & $5(6.84)$ \\
\hline Mucinous adenocarcinoma & $6(8.21)$ \\
\hline Adenosquamous carcinoma & $1(1.36)$ \\
\hline \multicolumn{2}{|l|}{ Complication } \\
\hline Wound site infection & $4(5.47)$ \\
\hline Pulmonary embolism & $1(1.36)$ \\
\hline Pneumonia & $3(4.1)$ \\
\hline Pleural effusion & $1(1.36)$ \\
\hline \multicolumn{2}{|l|}{ Hospitalization period (days) } \\
\hline $\begin{array}{l}\text { Mean } \pm \text { SD } \\
\text { Min - Max (median) }\end{array}$ & $\begin{array}{l}10,11 \pm 4,77 \\
7-40(9)\end{array}$ \\
\hline Adjuvant chemotherapy & $62(84.9 \%)$ \\
\hline \multicolumn{2}{|l|}{ Total number of lymph nodes } \\
\hline $\begin{array}{l}\text { Mean } \pm \text { SD } \\
\text { Min-max (median) }\end{array}$ & $\begin{array}{l}21,29 \pm 11,59 \\
4-56(19)\end{array}$ \\
\hline \multicolumn{2}{|l|}{ Number of metastatic lymph nodes } \\
\hline $\begin{array}{l}\text { Mean } \pm \text { SD } \\
\text { Min-max (median) }\end{array}$ & $\begin{array}{l}7,63 \pm 9,56 \\
0-44(5)\end{array}$ \\
\hline \multicolumn{2}{|l|}{ N-ratio } \\
\hline $\begin{array}{l}\text { Mean } \pm \text { SD } \\
\text { Min-max (median) }\end{array}$ & $0,32 \pm 0,31(0,25)$ \\
\hline \multicolumn{2}{|l|}{ Follow-up (month) } \\
\hline $\begin{array}{l}\text { Mean } \pm \text { SD } \\
\text { Min-max (median) }\end{array}$ & $\begin{array}{c}19,38 \pm 15,84 \\
1-61(14)\end{array}$ \\
\hline Mortality & $23(31.5 \%)$ \\
\hline Average estimated survival time (months) & 40.921 \\
\hline $\begin{array}{c}\begin{array}{c}\text { Values are presented as number and percentages } \\
\text { deviation }\end{array} \\
\end{array}$ & 6). SD: standard \\
\hline
\end{tabular}


Table 2 - Comparison between Group 1 and Group (N=73).

\begin{tabular}{|c|c|c|c|}
\hline Characteristics & $\begin{array}{c}\text { Group } 1 \\
\text { Ratio }<0.32 \\
(n=44)\end{array}$ & $\begin{array}{c}\text { Group } 2 \\
\text { Ratio } \geq 0.32 \\
(n=29)\end{array}$ & $P$-value \\
\hline \multicolumn{4}{|l|}{ Gender } \\
\hline Male & $34(77.3)$ & $22(75.9)$ & \multirow{2}{*}{0.889} \\
\hline Female & $10(22.7)$ & $7(24.1)$ & \\
\hline Age & $66.57 \pm 12.31(67.50)$ & $66.38 \pm 11.06(67)$ & 0.947 \\
\hline \multicolumn{4}{|l|}{ Presence of comorbidities } \\
\hline No & $24(54.5)$ & $16(55.2)$ & \multirow{2}{*}{0.669} \\
\hline yes & $20((45.5)$ & $13(44.8)$ & \\
\hline \multicolumn{4}{|l|}{ Operation width } \\
\hline $\begin{array}{l}\text { Subtotal gastrectomy + } \\
\text { D2 LN Dissection }\end{array}$ & $26(59.1)$ & $16(55.2)$ & \multirow{2}{*}{0.74} \\
\hline $\begin{array}{l}\text { Total gastrectomy }+ \\
\text { D2 Lymph node dissection }\end{array}$ & $18(40.9)$ & $12(44.8)$ & \\
\hline Cholecystectomy & $5(11.4)$ & $3(10.3)$ & 0.892 \\
\hline Splenectomy & $3(6.8)$ & $1(3.4)$ & 0.536 \\
\hline Hospitalization period (days) & $10.68 \pm 5.91(9)$ & $9.24 \pm 1.92(9)$ & 0.485 \\
\hline Chemotherapy & $36(81.8 \%)$ & $26(89.7)$ & 0.36 \\
\hline TLN & $18.77 \pm 9.36(19)$ & $25.10 \pm 13.64(24)$ & 0.04 \\
\hline MLN & $2.14 \pm 2.51(1)$ & $15.97 \pm 10.30(13)$ & $<0.001$ \\
\hline Follow-up & $22.84 \pm 15.47(22.5)$ & $14.14 \pm 15.19(8)$ & 0.009 \\
\hline Mortality & $8(18.2)$ & $15(51.7)$ & 0.003 \\
\hline $\begin{array}{l}\text { Average estimated survival time } \\
\text { (months) }\end{array}$ & 48.01 & 24.22 & 0.001 \\
\hline
\end{tabular}

$(p=0.485)$. The rate of postoperative chemotherapy treatment was similar in both groups $(81.8 \%$ vs. $89.7 \%)$. The average TLNs retrieved from the patients were $25.10 \pm 13.64$ in Group 2 patients and $18.77 \pm 9.36$ in Group 1 patients $(p=0.04)$. In Group 2, the MLN averages removed were determined to be $15.97+10.30$ and $2.14 \pm 2.51$ in Group $1(p<0.001)$. The mortality rates between the 2 groups were $18 \%$ and $51.7 \%$, respectively, and were highly statistically significant $(p=0.003)$. There was a significant difference in the average estimated survival analysis for both groups: Group 2's expected survival time was 24.22 months, and Group 1's was $48.01(p=0.001)$ (Table 2). For the overall group, the average estimated survival time was 40.92 months (Figure 1).

The cut-off value for optimally discriminating patients according to the development of mortality was 0.32 with $65.2 \%$ sensitivity and $72 \%$ specificity; it was statistically significant in the ROC analysis $(p=0.003)$. A ratio greater than 0.32 increased the risk of mortality within 4 years by 4.8 -fold, which was statistically significant (AVE 4.821 [95\%CI 1.675-13.876], $p=0.003$ ) (Table 3) (Figure 2).

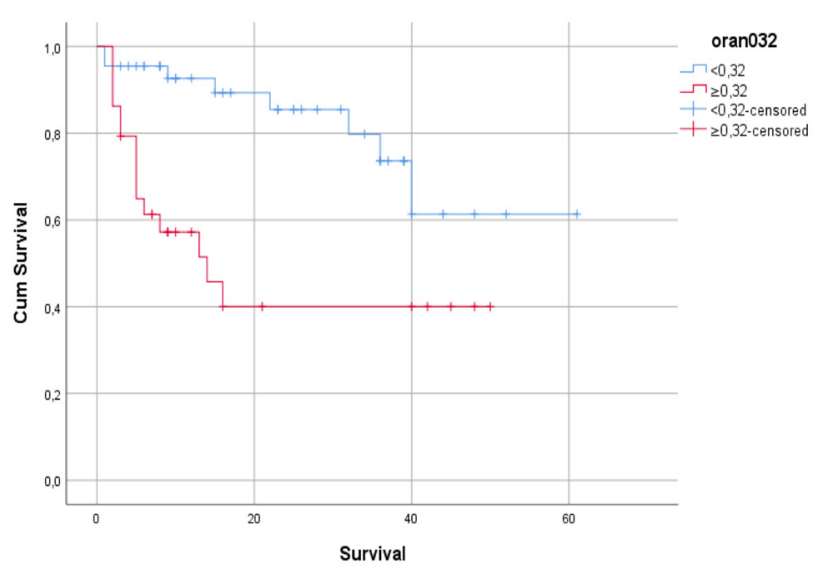

Figure 1 - Survival curve according to $\mathrm{N}$-ratio ratios.

Discussion. Lymph node dissection is critical not only for gastric cancer treatment, but also for correct staging and prognosis prediction. The clinical effects of lymph node dissection in gastric cancer are rather substantial when compared to other types of gastrointestinal tract cancer. 
Table 3 - Relationship to 4-year mortality by N-ratio.

\begin{tabular}{cccccccccccc}
\hline & \multirow{4}{*}{ Cut-off } & \multicolumn{4}{c}{ Diagnostic values } & \multicolumn{3}{c}{ ROC curve } & \multicolumn{3}{c}{ Odds ratio } \\
& & Sensitivity & Specificity & PPV & NPV & Area (SE) & 95\% CI & $P$-value & Odds ratio & $95 \%$ CI & $P$-value \\
\hline \multirow{2}{*}{ N-ratio } & 0.32 & $65.20 \%$ & $72.00 \%$ & 51.70 & $81.80 \%$ & $0.700(0.069)$ & $0.565-0.835$ & 0.006 & 4.821 & $1.675-13,876$ & 0.003 \\
\hline \multicolumn{4}{c}{ PPV: positive predictive palue, NPV: negative predictive value, SE: standard error, CI: confidence interval } \\
\hline
\end{tabular}

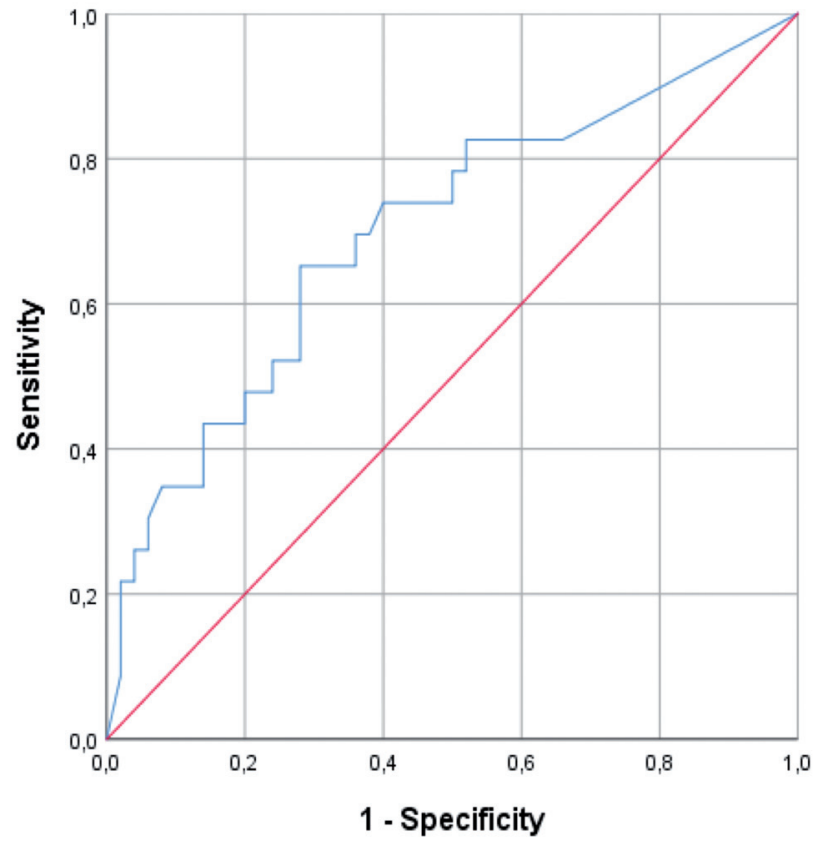

Figure 2 - A 4-year mortality receiver operating characteristics by N-ratio. Diagonal segments are produced by ties.

The American Joint Committee on Cancer (AJCC) tumor node metastasis (TNM) staging is widely utilized in daily practice due to its simplicity and repeatability. It has also been questioned due to a potential limitation of stage migration in gastric cancer, and it has been suggested that the lymph node ratio be used to overcome this staging problem for patients with lymph node who have been studied in small numbers; the hypothesis is that the $\mathrm{N}$-ratio may represent the true burden of lymph node metastases. ${ }^{14,15}$ In a large cohort of conventional lymph node dissections, N-Ratio staging was found to be superior to AJCC TNM N-staging. ${ }^{16}$ The N-ratio cut-off value in this study was 0.32 . Group 2 had dramatically reduced survival with increased mortality and worse prognosis.

In gastric cancer, lymph node metastases is a significant prognostic factor. ${ }^{17}$ Huang et $\mathrm{al}^{18}$ determined that an N-ratio of less than 0.3 enhanced survival in 236 patients diagnosed with gastric cancer originating from the cardia and fundus and having D2 curative resection. Know et $\mathrm{al}^{19}$ classified the number of dissected lymph nodes to metastatic lymph nodes into 4 categories: $0 \%, 1-25 \%, 26-50 \%$, and $>50 \%$, with 5 -year survival rates of $83 \%, 66 \%, 30 \%$, and $23 \%$, respectively. In a study of 1654 gastric cancer patients, Siewert et $\mathrm{al}^{20}$ reported that lymph node involvement rates greater than $20 \%$ were the most important poor prognostic indication. The MLN removed increases in patients who have undergone extended lymphadenectomy, thus prolonging survival. ${ }^{21}$ Here, the cut-off value was determined as 0.32 . The overall survival and prognosis of the patients in Group 1 were significantly better than the other group in this study based on the cut-off value $(p=0.003)$.

Nelen et $\mathrm{al}^{22}$ support our conclusions with an LNR greater than 0.3 having a lower survival rate. Their data confirm our Kaplan Meier survival curve, which we acquired when the 2 curves in between were ignored. In addition, a meta-analysis of 27 studies indicated that a high $\mathrm{N}$-ratio was linked to a shorter survival. ${ }^{23}$ The LNR ratio in this study was 0.32 , which is consistent with the literature. The duration dropped to 48 months in Group 1 and 24 months in Group 2 based on the average survey of the patients. In another study, patients with LNR greater than 0.4 had a median survival period of 20.5 months. Patients with an LNR of less than or equal to 0.4 had a longer median survival time (47.0 months). This implies that the LNR was useful in determining the prognosis of patients with less than 15 lymph nodes evaluated; as the LNR increased, the median survival time fell. ${ }^{20}$

Various studies have shown that the lymph node in the TNM classification used in gastric cancer staging should be re-determined based on N-Ratio ratios rather than the number of lymph node retained. ${ }^{18,21,24} \mathrm{~A}$ statistically significant difference was observed when the groups formed using $\mathrm{N}$-ratio cut-offs were compared in terms of total survival time $(p=0.001)$ (Figure 2$)$.

One of the important prognostic factors in gastric cancer is the $\mathrm{N}$-ratio ratio, which has been reported in recent studies. ${ }^{25}$ In survival analyses, the rate of metastatic lymph nodes was found to be an independent factor for survival, and most studies proposed reclassification of 
$\mathrm{N}$ according to this rate. ${ }^{17,25-27}$ In this study, "the ratio of metastatic to total lymph nodes" was determined to be the factor that had a statistically significant effect on survival in the survival analysis conducted to determine the effect of the data evaluated on survival $(p<0.001)$. Recent research suggests that the positive lymph node ratio (LNR) and the log odds of positive lymph nodes (LODDS) may be more accurate predictors of postoperative survival in gastric cancer patients than the AJCC N stage. ${ }^{17,28}$

We found a cut-off value of 0.32 , and patients exceeding this value have significantly lower survival and higher mortality. A ratio greater than 0.32 statistically raised the mortality risk in 4 years by 4.8 times (AVE 4.821 [95\%CI 1.675-13.876], $p=0.003)$. In other words, it has a negative effect on the prognosis. Other studies support this study, but because of the variation in lymph node dissected between centers, determining the lymph node ratio cut-off value for each stage is difficult. More multicenter studies are needed to find universal cut-off values. ${ }^{29,30}$

Study limitation. This study is a retrospective study with a small number of cases, and the follow-up period is limited to 5 years.

It is possible to use $\mathrm{N}$-ratio as a more significant predictor of survival than $\mathrm{N}$-stage in terms of future TNM (tumor-node-metastasis) staging as well as future staging in patients who are scheduled to have surgical resection and lymph node dissection for gastric cancer. Determining a universally cut-off value in the lymph node ratio is extremely challenging because the number of lymph nodes removed varies substantially between clinics due to varying surgical approach practices. However, this universal cut-off value can be determined with many prospective and long-term follow-up studies conducted in multicenter and even multinational trials. In patients undergoing curative resection for gastric cancer, the LNR level, rather than the LN number, may provide more accurate results in predicting prognosis. As a result, the LNR could become a new indicator for assessing prognosis following curative gastrectomy and improving the current TNM staging system.

Acknowledgment. The authors would like to express their gratitude to American Manuscript Editors for their assistance with English language editing.

\section{References}

1. Bray F, Ferlay J, Soerjomataram I, et al Global cancer statistics 2018: GLOBOCAN estimates of incidence and mortality worldwide for 36 cancers in 185 countries. CA Cancer J Clin 2018; 68: 394-424.
2. Zhang YX, Yang K. Significance of nodal dissection and nodal positivity in gastric cancer. Transl Gastroenterol Hepatol 2020; 5: 17.

3. Pan S, Wang P, Xing Y, Li K, Wang Z, Xu H, et al. Retrieved lymph nodes from different anatomic groups in gastric cancer: a proposed optimal number, comparison with other nodal classification strategies and its impact on prognosis. Cancer Commun 2019; $39: 49$

4. Eshuis WJ, van Barge Henegouwen MI, Draaisma WA, Gisbert SS. Compliance to D2 lymphadenectomy in laparoscopic gastrectomy. Updates Surg 2018; 70: 197-205.

5. Zhang N, Bai H, Deng J, Wang W, Sun Z, Wang Z, et al. Impact of examined lymph node count on staging and long-term survival of patients with node-negative stage III gastric cancer: a retrospective study using a Chinese multi-institutional registry with Surveillance, Epidemiology, and End Results (SEER) data validation. Ann Transl Med 2020; 8: 1075-1091.

6. Kinami S, Ohnishi T, Nakamura N, Jiang ZY, Miyata T, Fujita $\mathrm{H}$, et al. Efficacy of the fat-dissociation method for nodal harvesting in gastric cancer. World J Gastrointest Surg 2020; 12: 277-286.

7. Baiocchi GL, Molfino S, Molteni B, Quarti, Arcangli G, Manenti S, et al. Fluorescence-guided lymphadenectomy in gastric cancer: a prospective western series. Updates Surg 2020; 72: 761-772.

8. Nakamura K, Ueyama T, Yao T, XuanV ZX, Ambe K, Adachi Y, et al. Pathology and prognosis of gastric carcinoma. Findings in 10,000 patients who underwent primary gastrectomy. Cancer 1992; 70: 1030-1037.

9. Lu J, Zheng CH, Cao LL, Li P, Xie JW, Wang JB, et al. The effectiveness of the 8th American Joint Committee on Cancer TNM classification in the prognosis evaluation of gastric cancer patients: A comparative study between the 7 th and 8 th editions. Eur J Surg Oncol 2017; 43: 2349-2356.

10. Biondi A, D’Ugo D, Cananzi FC, Papa V, Borasi A, Sicoli F, et al. Does a minimum number of 16 retrieved nodes affect survival in curatively resected gastric cancer? Eur J Surg Oncol 2015; $41: 779-786$.

11. Lee YC, Yang PJ, Zhong Y, Clancy TE, Lin MT, Wang J. Lymph node ratio-based staging system outperforms the seventh AJCC system for gastric cancer: Validation analysis with National Taiwan University Hospital Cancer Registry. Am J Clin Oncol 2017; 40: 35-41

12. Xu J, Bian YH, Jin X, Cao H. Prognostic assessment of different metastatic lymph node staging methods for gastric cancer after D2 resection. World J Gastroenterol 2013; 19: 1975-1983.

13. Tóth D, Bíró A, Varga Z, Török M, Árkosy P. Comparison of different lymph node staging systems in prognosis of gastric cancer: A bi-institutional study from Hungary. Chin J Cancer Res 2017; 29: 323-332.

14. Marchet A, Mocellin S, Ambrosi A, Morgagni P, Garcea D, Marrelli $\mathrm{D}$, et al. The ratio between metastatic and examined lymph nodes ( $\mathrm{N}$ ratio) is an independent prognostic factor in gastric cancer regardless of the type of lymphadenectomy: results from an Italian multicentric study in 1853 patients. Ann Surg 2007; 245: 543-552.

15. Turhan VB, Ünsal A, Gök HF, Öztürk B, Öztürk D, Simsek GG, et al. Predictive value of preoperative neutrophil-lymphocyte and platelet-lymphocyte ratio in determining the stage of colon tumors. Cureus 2021; 13: e18381. 
16. Chen S, Rao H, Liu J, Geng Q, Guo J, Kong P, et al. Lymph nodes ratio based nomogram predicts survival of resectable gastric cancer regardless of the number of examined lymph nodes. Oncotarget 2017; 8: 45585-45596.

17. Agnes A, Biondi A, Cananzi FM, Rausei S, Reddavid R, Laterza $\mathrm{V}$, et al. Ratio-based staging systems are better than the 7 th and 8th editions of the TNM in stratifying the prognosis of gastric cancer patients: A multicenter retrospective study. J Surg Oncol 2019; 119: 948-957.

18. Huang CM, Lin BJ, Lu HS, Zhang XF, Li P, Xie JW. Prognostic impact of metastatic lymph node ratio in advanced gastric cancer from cardia and fundus. World J Gastroenterol 2008; 21; 14: 4383-4388.

19. Know Sj, Kim GS, Prognostic significance of lymph node metastasis in advanced carsinoma of the stomach. Br J Surg 1996; 83: 1600-1603.

20. Siewert JR, Böttcher K, Stein HJ, Roder JD. Relevant prognostic factors in gastric cancer: ten-year results of the German Gastric Cancer Study. Ann Surg 1998; 228: 449-461.

21. Hou Y, Wang X, Chen J. Prognostic significance of metastatic lymph node ratio: the lymph node ratio could be a prognostic indicator for patients with gastric cancer. World J Surg Onc 2018; 16: 198.

22. Nelen SD, van Steenbergen LN, Dassen AE, van der Wurff AA, Lemmens VE, Bosscha $\mathrm{K}$, et al. The lymph node ratio as a prognostic factor for gastric cancer. Acta Oncol 2013; 52: 1751-1759.

23. Jiang Zhu, Zhao Xue, Shumei Zhang, et al. Integrated analysis of the prognostic role of the lymph node ratio in node-positive gastric cancer: A meta-analysis. International Journal of Surgery 2018; 57: 76-83.
24. Wang W, Sun Z, Deng JY, Qi XL, Feng XY, Fang C, et al. A novel nomogram individually predicting disease-specific survival after D2 gastrectomy for advanced gastric cancer. Cancer Commun (Lond) 2018; 38: 23.

25. Gu P, Deng J, Sun Z, Wang Z, Wang W, Liang H, et al. Superiority of log odds of positive lymph nodes (LODDS) for prognostic prediction after gastric cancer surgery: a multiinstitutional analysis of 7620 patients in China. Surg Today 2021; 51: 101-110.

26. Wang XQ, Bao M, Zhang C. Prognostic value of different lymph node staging methods for node-positive cardia gastric cancer: a register-based retrospective cohort study. BMJ Open 2021; 11: e050378.

27. Xu Z, Jing J, Ma G. Development and validation of prognostic nomogram based on log odds of positive lymph nodes for patients with gastric signet ring cell carcinoma. Chin J Cancer Res 2020; 32: 778-793.

28. Chen YR, Wang MQ, Li YT, Li P, Ouyang SS, Xu HW, et al. Prognostic performance of different lymph node classification systems in young gastric cancer. J Gastrointest Oncol 2021: 1285-1300.

29. Cao H, Tang Z, Yu Z, Wang Q, Li Z, Lu Q, et al Comparison of the 8th union for international cancer control lymph node staging system for gastric cancer with two other lymph node staging systems. Oncol Lett 2019; 17: 1299-1305.

30. Kong SH. Lymph node ratio system for $\mathrm{N}$ staging of gastric cancer: challenging for universal application but useful for the prognostic prediction of individual patients. J Gastric Cancer 2021; 21: 1-3. 